\title{
Prognostic significance of in situ and plasma levels of transforming growth factor $\beta 1,-2$ and -3 in cutaneous melanoma
}

\author{
MING-RUI TANG, YU-XIN WANG, SHU GUO, SI-YUAN HAN, HE-HUAN LI and SHI-FENG JIN \\ Department of Plastic Surgery, The First Affiliated Hospital of China Medical University, \\ Shenyang, Liaoning 110001, P.R. China
}

Received March 25, 2014; Accepted January 2, 2015

DOI: $10.3892 / \mathrm{mmr} .2015 .3250$

\begin{abstract}
Melanoma is an aggressive type of cutaneous malignancy. Transforming growth factor (TGF)- $\beta$ has been demonstrated to be an important mediator of tumor progression. However, to the best of our knowledge, the systemic roles of plasma TGF- $\beta$ and TGF- $\beta$ in situ have not been investigated in Han Chinese melanoma patients. The results of the present study demonstrated that the in situ and plasma levels of TGF- $\beta 1$, TGF- $\beta 2$ and TGF- $\beta 3$ protein and messenger RNA were significantly elevated in tumor tissues compared with those of normal tissues. The survival rates of the patients which were triple-positive (TGF- $\beta 1^{+}, \mathrm{TGF}-\beta 2^{+}$and TGF- $\left.\beta 3^{+}\right)$were found to be markedly decreased compared to those which were single- $\left(\mathrm{TGF}-\beta 1^{+}, \mathrm{TGF}-\beta 2^{+}\right.$or $\left.\mathrm{TGF}-\beta 3^{+}\right)$or double-positive (TGF- $\beta 1^{+}$, TGF- $\beta 2^{+}$; TGF- $\beta 2^{+}$, TGF- $\beta 3^{+}$; or TGF- $\left.\beta 1^{+}, \mathrm{TGF}-\beta 3^{+}\right)$. These results may therefore contribute to the use of TGF- $\beta$ as a prognostic biomarker, and to the development of novel therapies for melanoma treatment.
\end{abstract}

\section{Introduction}

Melanoma was reported to have the highest mortality rate of all skin cancers; however, it only accounts for $<5 \%$ of skin cancer cases (1). The incidence of melanoma in the general population was shown to be increasing rapidly, with the estimated number of cases expected to treble over the next 30 years (2). Therefore, the identification of melanoma-specific genes, which may result in the elucidation of novel markers for monitoring the disease status or novel therapeutic targets, is of great interest (3).

Transforming growth factor (TGF)- $\beta$ is secreted as a latent precursor, which becomes proteolytically activated to form a homodimer of two $12.5 \mathrm{kDa}$ polypeptides, which are linked

Correspondence to: Dr Ming-Rui Tang, Department of Plastic Surgery, The First Affiliated Hospital of China Medical University, 155 Nanjing North Street, Heping, Shenyang, Liaoning 110001, P.R. China

E-mail: doctor_tangmingrui@163.com

Key words: transforming growth factor- $\beta$, melanoma, plasma, prognosis, metastasis by a disulfide bond $(4,5)$. Three isoforms of TGF- $\beta$ have been identified in humans, which include TGF- $\beta 1$, TGF- $\beta 2$ and TGF- $\beta 3$ (6). Active TGF- $\beta$ isoforms were found to be highly selective and bind with high affinity to the membrane-spanning serine/threonine kinase receptor, TGF- $\beta$ receptor type II (T $\beta$ RII), which subsequently recruits and activates TGF- $\beta$ receptor type I (5). TGF- $\beta$ signaling was reported to downregulate epithelial tumorigenesis through inhibiting cell cycle progression, enhancing apoptosis as well as establishing genomic stability and cellular senescence (7).

Numerous studies have demonstrated the roles of TGF- $\beta$ isoforms in melanoma (8-10). However, to the best of our knowledge, no systemic studies to date have elucidated the association between in situ or plasma TGF- $\beta$ isoforms and the Chinese Han melanoma patients. The aim of the present study was to investigate the in situ and plasma levels of TGF- $\beta 1$, $\beta 2$ and $\beta 3$ in melanoma patients and healthy volunteers. In addition, the present study aimed to improve the current understanding of the association between tumor and inflammation.

\section{Materials and methods}

Subjects. Tissue specimens were obtained from 20 melanoma patients, prior to treatment, at the Department of Plastic Surgery, The First Affiliated Hospital of China Medical University (Shenyang, China), between January 2006 and December 2010. Blood samples were collected from the same patients as well as 20 healthy volunteers without melanoma (selected according to gender matching), and added to EDTA-containing tubes (Corning Life Sciences Co. Ltd, Shanghai, China), which were stored on ice within $30 \mathrm{~min}$. The samples were immediately centrifuged at 3,000 x g for $20 \mathrm{~min}$; the plasma was then frozen and stored at $-70^{\circ} \mathrm{C}$ until further use. The present study was performed in compliance with the Helsinki Declaration, all patients provided written informed consent for participation and the procedure was approved by the Ethics Committee of The First Affiliated Hospital of China Medical University. Healthy volunteers were nurses, doctors, students and patients at The First Affiliated Hospital of China Medical University.

Immunoblotting. Tissues were lysed in lysis buffer (20 mM Tris- $\mathrm{HCl}, 150 \mathrm{mM} \mathrm{NaCl}, 2 \mathrm{mM}$ EDTA and 
1\% Triton-X100) containing a protease inhibitor cocktail (Sigma-Aldrich, St. Louis, MO, USA). Proteins (30 $\mu$ g per lane) were separated using 10\% SDS-PAGE (Bio-Rad Laboratories, Inc., Shanghai, China) and transferred to polyvinylidene fluoride membranes (Millipore Corp., Billerica, MA, USA). Western blot analysis was then performed using the following primary antibodies: Mouse monoclonal immunoglobulin (Ig) $\mathrm{G}_{1}$ TGF- $\beta 1$ (1:200; sc-130348), goat polyclonal IgG TGF- $\beta 2$ (1:200; sc-31610), mouse monoclonal IgM TGF- $\beta 3$ (1:200; sc-166861) and mouse monoclonal $\operatorname{IgG}_{1} \beta$-actin $(1: 1,000$; sc-47778), which were all purchased from Santa Cruz Biotechnology, Inc. (Dallas, TX, USA). The reaction was followed by probing with peroxidase-coupled secondary antibodies, including monoclonal anti-goat $\operatorname{IgG}(1: 1000$; RPN4301), monoclonal anti-mouse IgM (1:1000; BR100838) or monoclonal anti-mouse IgG (1:2000; RPN4201) antibodies (Amersham Biosciences, Needham, MA, USA). Incubation with antibodies was performed in $1.5 \%$ bovine serum albumin (Sigma-Aldrich) in Tris-buffered saline with $0.1 \%$ Tween (Sigma-Aldrich). Detection of the immune complexes was performed using an enhanced chemiluminescence western blot detection kit (Takara Bio, Inc., Dalian, China).

Reverse transcription quantitative polymerase chain reaction (RT-qPCR). Total tissular RNA was isolated using TRIzol reagent (Invitrogen Life Technologies, Carlsbad, CA, USA). Complementary (c)DNA was then synthesized from $1 \mu \mathrm{g}$ total RNA using SuperScript II reverse transcriptase (Invitrogen Life Technologies) according to the manufacturer's instructions. Expression levels of tissular TGF- $\beta 1$, TGF- $\beta 2$ and TGF- $\beta 3$ messenger (m)RNA were quantitated by qPCR using the ABI Prism 7500 Real-Time PCR System (Applied Biosystems, Life Technologies) with power SYBR ${ }^{\circledR}$ Green PCR Master Mix (Takara Bio, Inc.). The following primer sets (Sangon Biotech Co., Ltd, Shanghai, China) were used: TGF- $\beta 1$ sense, 5 '-GTGGAGAATGTATACAAGCAGG-3' and antisense, 5'-CTAATGTAAGGCATCACAGTC-3'; TGF- $\beta 2$ sense, 5'-TCTAGGGTGGAAATGGATACACGAACC-3' and antisense, 5'-TGTTACAAGCATCATCGTTGTCGTCG-3'; TGF- $\beta 3$ sense, 5'GATGCATCCCACTTGCTG-3' and antisense, 5'-CAGGTGGCATTGAAGGA-3'; and GAPDH sense, 5'GAAGGTGAAGGTCGGAGT-3' and antisense, 5'-CATGGGTGGAATCATATTGGAA-3'. The qPCR conditions were as follows: One cycle at $95^{\circ} \mathrm{C}$ for $10 \mathrm{~min}$, followed by 40 cycles at $95^{\circ} \mathrm{C}$ for $15 \mathrm{sec}$ and $60^{\circ} \mathrm{C}$ for $1 \mathrm{~min}$. The $\Delta \Delta \mathrm{Ct}$ methods was used for data analysis.

Immunohistochemical staining. All reagents used for immunohistochemistry were obtained from Beyotime Institute of Biotechnology (Beijing, China). All tissues were fixed in $10 \%$ buffered formalin and embedded in paraffin according to standard methods. Sections $(4 \mu \mathrm{m})$ were then deparaffinized in xylene. Endogenous peroxidase was blocked with $3 \%$ hydrogen peroxide in deionized water for $20 \mathrm{~min}$. Antigen retrieval was performed in citrate buffer $\left(10 \mathrm{mM}, \mathrm{pH}\right.$ ) for $30 \mathrm{~min}$ at $95^{\circ} \mathrm{C}$. Sections were immunostained with polyclonal antibodies for TGF- $\beta 1$ (sc-130348; 1:100), TGF- $\beta 2$ (sc-31610; 1:50) or TGF- $\beta 3$ (sc-166861; 1:50) for $60 \mathrm{~min}$ at $37^{\circ} \mathrm{C}$, followed by biotinylated secondary antibodies for $30 \mathrm{~min}$ and subsequently reacted with horseradish peroxidase for $30 \mathrm{~min}$. For visualization, hydrogen

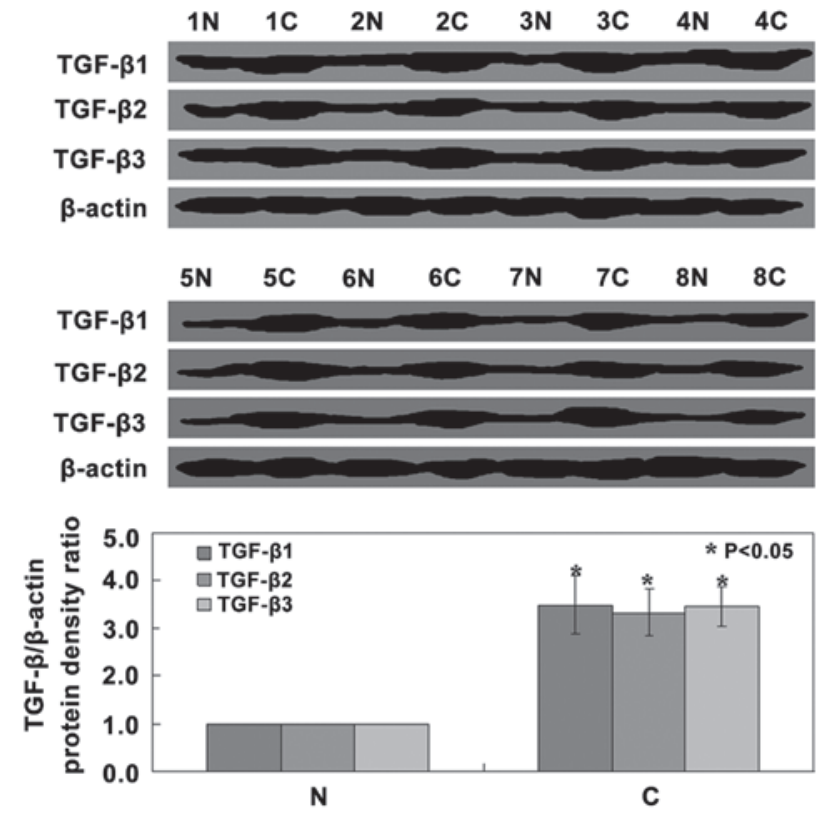

Figure 1. Western blot analysis of the protein expression of three TGF- $\beta$ isoforms in melanoma tissue. Representative blots and quantitative analysis of TGF- $\beta 1$, TGF- $\beta 2$ and TGF- $\beta 3$ expression in paired melanoma and corresponding normal tissues. $\beta$-actin was used as an internal control. Values are presented as the mean \pm standard deviation $(n=20)$. ${ }^{*} \mathrm{P}<0.05$ vs. N. N, normal tissue; $\mathrm{C}$, cancerous tissue; TGF- $\beta$, transforming growth factor $\beta$.

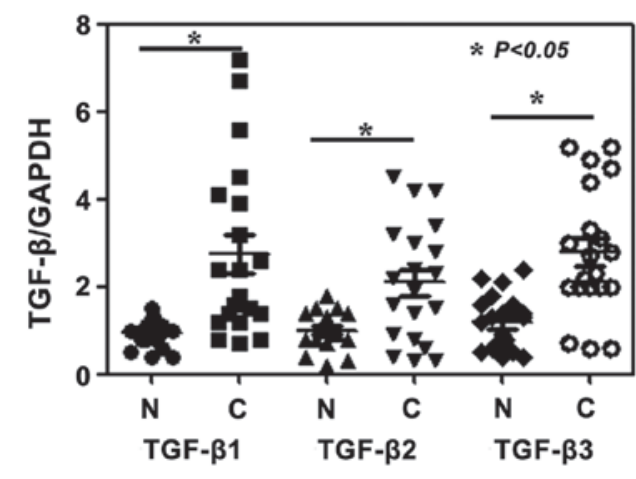

Figure 2. Messenger RNA expression levels of TGF- $\beta 1$, TGF- $\beta 2$ and TGF- $\beta 3$ in paired melanoma and corresponding normal tissues, as determined by reverse transcription quantitative polymerase chain reaction $(n=20)$. GADPH was used as an internal control. ${ }^{*} \mathrm{P}<0.05$ vs. N. N, normal tissue; $\mathrm{C}$, cancer tissue; TGF- $\beta$, transforming growth factor $\beta$.

peroxide-activated diamino benzidine was applied. Five-minute washes in phosphate-buffered saline were performed between each step. Tissue sections were lightly counter-stained with hematoxylin, dehydrated using a graded series of ethanol, cleared with xylene and then mounted in mounting medium. Normal tissue was used as a control and sections treated without primary antibodies were used as negative controls.

ELISAs. Plasma levels of TGF- $\beta 1$ (PDB110B; Human TGF- $\beta 1$ Quantikine ELISA Kit; R\&D Systems, Minneapolis, MN, USA), TGF- $\beta 2$ (PDB250 Human TGF- $\beta 2$ Quantikine ELISA Kit; R\&D Systems) and TGF- $\beta 3$ (OK-0265; OmniKine ${ }^{\mathrm{TM}}$ Human TGF- $\beta 3$ ELISA Kit; Assay Biotechnology, Sunnyvale, CA, USA) were detected using their respective commercially available ELISA kits. 


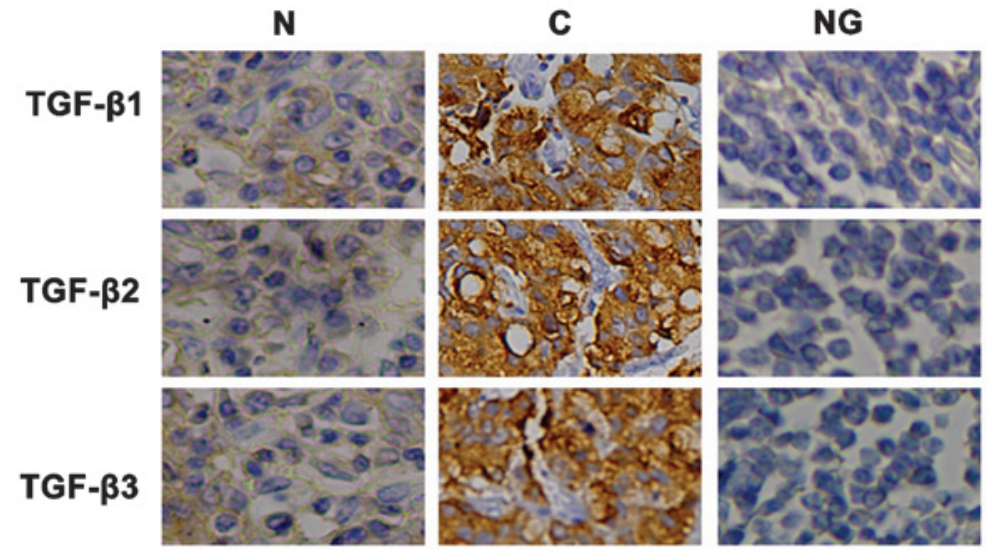

Figure 3. Immunohistochemical staining for TGF- $\beta 1$, TGF- $\beta 2$ and TGF- $\beta 3$ protein expression in melanoma and corresponding normal tissues. TGF- $\beta$ isoforms stained yellow with granules and localized to the cytoplasm. Nuclei were counterstained with hematoxylin. N, normal tissue; $\mathrm{C}$, cancer tissue; $\mathrm{NG}$, negative control; TGF- $\beta$, transforming growth factor $\beta$.

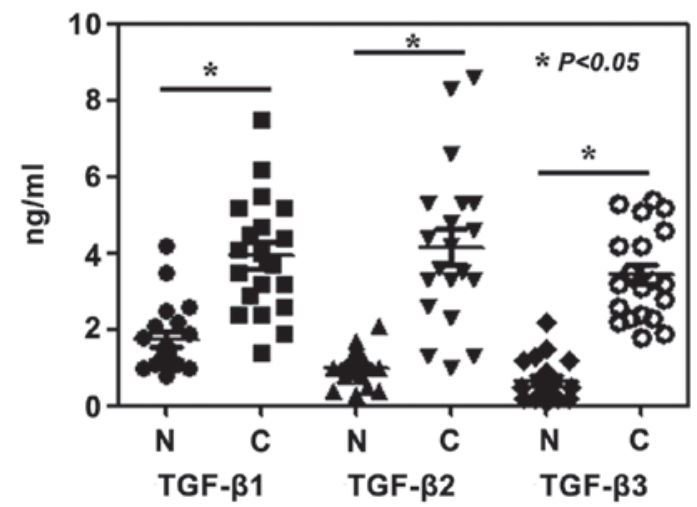

Figure 4. Plasma TGF- $\beta 1$, TGF- $\beta 2$ and TGF- $\beta 3$ protein expression levels of melanoma patients and healthy volunteers, as detected using ELISA. ${ }^{*} \mathrm{P}<0.05$ vs. N. N, normal tissue; C, cancer tissue; TGF- $\beta$, transforming growth factor $\beta$.

Statistical analysis. Values are presented as the mean \pm standard deviation. Differences between groups were analyzed using the Student's t-test for continuous variables. Survival time was calculated from the date of melanoma diagnosis to the date of succumbing to the disease or last follow-up. The Kaplan-Meier method (11) was used to evaluate the effects of TGF- $\beta$ expression on the overall survival of patients. Statistical analysis was performed using the SPSS 17.0 software (International Business Machines, Armonk, NY, USA) and $\mathrm{P}<0.05$ was considered to indicate a statistically significant difference between values.

\section{Results}

TGF- $\beta 1, \beta 2$ and $\beta 3$ expression in human melanoma specimens. Western blot analysis of tissue samples revealed that TGF- $\beta 1$, TGF- $\beta 2$ and TGF- $\beta 3$ protein expression levels in cancer tissue were all significantly increased compared with those in normal tissue $(\mathrm{P}<0.05)$ (Fig. 1). In order to determine whether TGF- $\beta 1$, TGF- $\beta 2$ and TGF- $\beta 3$ mRNA expression levels were also increased, RT-qPCR analysis was performed. The results showed that the expression levels of TGF- $\beta 1$, TGF- $\beta 2$ and TGF- $\beta 3$ mRNA were coincident with those of the
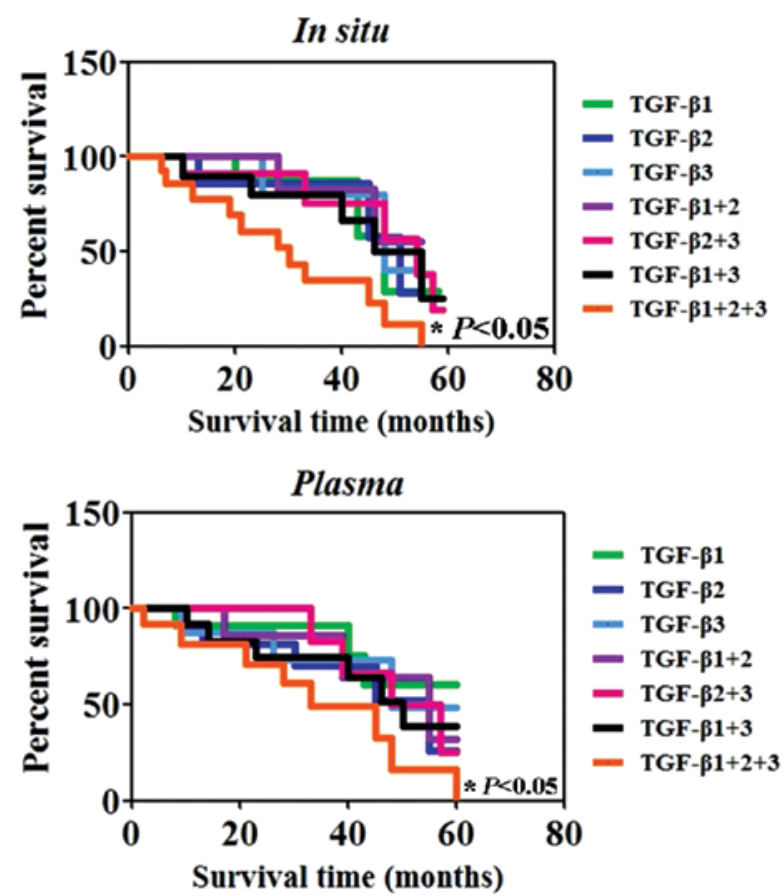

Figure 5. Correlations between TGF- $\beta$ isoforms single-, double- or triple-positive protein expression, in situ or plasma, and melanoma patient prognosis, as determined using the Kaplan-Meier method. $\mathrm{P}<0.05$ between the values of the patients and the healthy controls. TGF- $\beta$, transforming growth factor $\beta$.

protein expression, namely significantly increased compared with those in normal tissue $(\mathrm{P}<0.05)$ (Fig. 2). As shown in Fig. 3, immunohistochemical staining revealed that TGF- $\beta 1$, TGF- $\beta 2$ and TGF- $\beta 3$ proteins were located in the cytoplasm of cancer cells. Furthermore, the plasma levels of TGF- $\beta 1$, TGF- $\beta 2$ and TGF- $\beta 3$ in malignant melanoma patients were significantly elevated compared with those in the healthy volunteers $(\mathrm{P}<0.05)$ (Fig. 4).

$T G F-\beta$ expression and the clinicopathological variables. The potential associations between the expression of TGF- $\beta$ and the clinicopathological characteristics of the patients enrolled in the present study were then determined. No significant associations were identified between TGF- $\beta 1$, TGF- $\beta 2$ and 


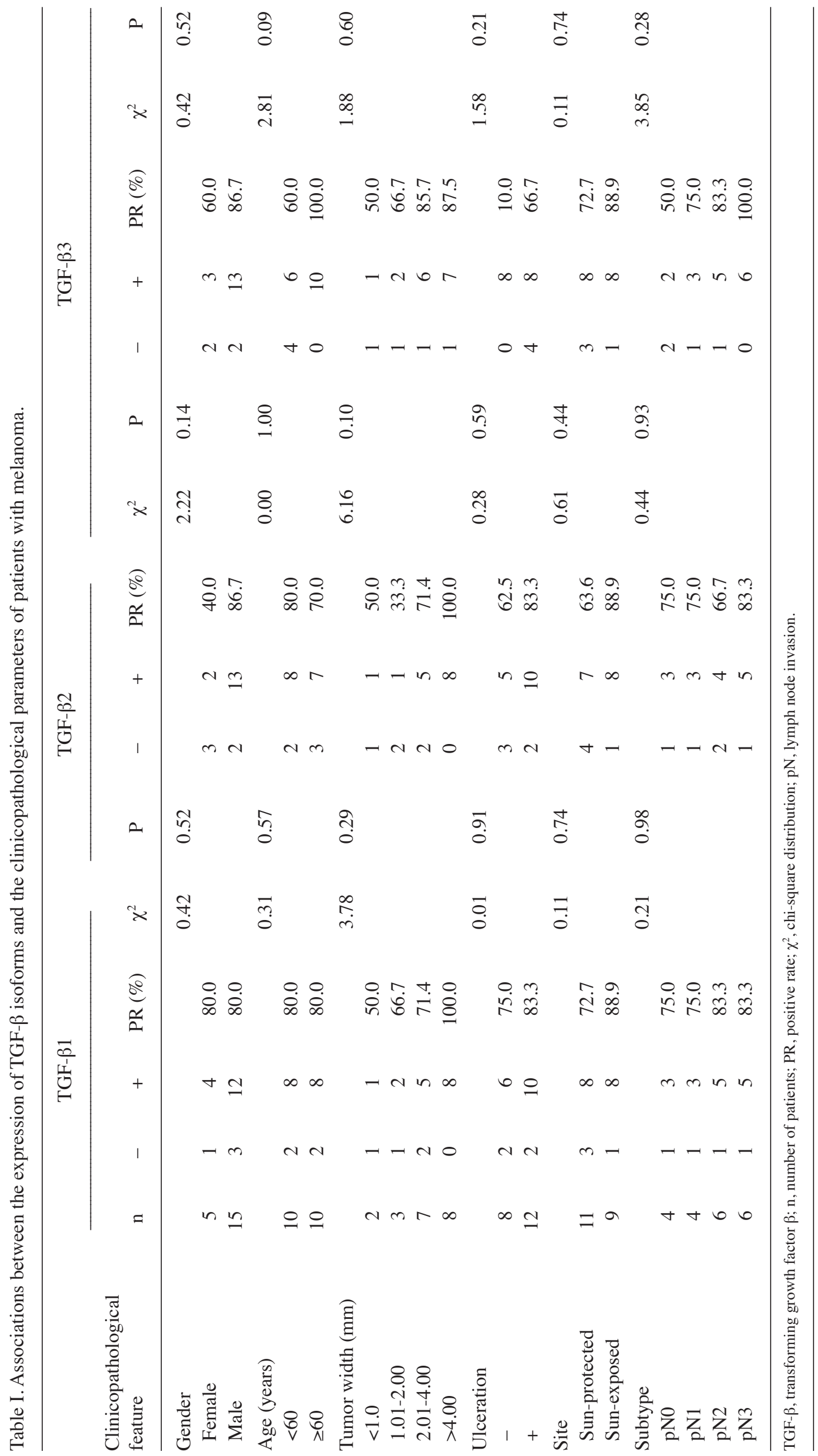


TGF- $\beta 3$ proteins and the clinicopathological characteristics of the patients with melanoma $(\mathrm{P}>0.05)$ (Table I). In order to investigate associations between the expression levels of TGF- $\beta$ and patient survival, the survival data from the 20 patients with melanoma enrolled in the present study, were assessed using the Kaplan-Meier method. The results showed that the survival rate of the triple-positive (TGF- $\beta 1^{+}$, TGF- $\beta 2^{+}$ and TGF- $\left.\beta 3^{+}\right)$patients were markedly decreased compared with those of patients who were found to be single-(TGF- $\beta 1^{+}$, TGF- $\beta 2^{+}$or TGF- $\beta 3^{+}$) or double-positive (TGF- $\beta 1^{+}$, TGF- $\beta 2^{+}$; TGF- $\beta 2^{+}$, TGF- $\beta 3^{+}$; or TGF- $\beta 1^{+}$, TGF- $\left.\beta 3^{+}\right)(\mathrm{P}<0.05)$ (Fig. 5), these results were comparable for in situ and plasma protein expression.

\section{Discussion}

TGF- $\beta$ is known to be an important regulator of tumor progression as well as a variety of biological processes, including cell proliferation, angiogenesis, migration, invasion and survival $(12,13)$. In the present study, the in situ and plasma expression levels of all three TGF- $\beta$ isoforms were investigated in melanoma patients. Previous studies have shown that melanoma cells produced TGF- $\beta 1$ (14) and that TGF- $\beta 1$ induced the death of surrounding healthy cells, thus eliminating their inhibitory effects on tumor growth (15). Overexpression of TGF- $\beta 1 \mathrm{mRNA}$ was identified in primary and metastatic melanomas (16); in addition, TGF- $\beta 2$ and TGF- $\beta 3$ were not found to be expressed in normal melanocytes, whereas they were expressed in nevi as well as early and advanced primary and metastatic melanomas, where they were associated with tumor progression (17). In concurrence with these previous studies, the present study confirmed that the in situ levels of TGF- $\beta 1$, TGF- $\beta 2$ and TGF- $\beta 3$ protein were significantly increased in the patients with melanoma.

The secretion of TGF- $\beta$ isoforms have been investigated in established melanoma cell lines (18). Krasagakis et al (19) performed a series of experiments to determine the systemic levels of TGF- $\beta$ isoforms in melanoma patients, the results of which demonstrated a marked increase in TGF- $\beta 1$ expression and a moderate increase in TGF- $\beta 2$ expression in the plasma of metastatic melanoma patients; however, no elevation was detected in TGF- $\beta 3$ plasma expression. By contrast, the results of the present study showed that the plasma levels of TGF- $\beta 1$, TGF- $\beta 2$ and TGF- $\beta 3$ proteins were significantly increased in melanoma patients compared with those of the healthy controls. The present study demonstrated that the survival rate of the triple-positive patients was markedly lower compared with that of single- or double-positive patients.

In conclusion, the results of the present study revealed that the expression levels of all three TGF- $\beta$ isoforms were significantly increased in melanoma patients. In addition, these results indicated that positive TGF- $\beta 1$, TGF- $\beta 2$ and TGF- $\beta 3$ expression was correlated with a poor survival of melanoma patients. This therefore suggested that TGF- $\beta 1$, TGF- $\beta 2$ and TGF- $\beta 3$ may serve as promising prognostic markers for patients with malignant melanoma.

\section{References}

1. Jemal A, Bray F, Center MM, et al: Global cancer statistics. CA Cancer J Clin 61: 69-90, 2011.

2. Diffey BL: The future incidence of cutaneous melanoma within the UK. Br J Dermatol 151: 868-872, 2004.

3. Sousa JF, Torrieri R, Silva RR, et al: Novel primate-specific genes, RMEL 1, 2 and 3, with highly restricted expression in melanoma, assessed by new data mining tool. PLoS One 5: e13510, 2010.

4. Massague J: How cells read TGF-beta signals. Nat Rev Mol Cell Biol 1: 169-178, 2000.

5. Derynck R and Zhang YE: Smad-dependent and Smad independent pathways in TGF-beta family signalling. Nature 425: 577-584, 2003.

6. Wu MY and Hill CS: Tgf-beta superfamily signaling in embryonic development and homeostasis. Dev Cell 16: 329-343, 2009.

7. Roberts $\mathrm{AB}$ and Wakefield LM: The two faces of transforming growth factor beta in carcinogenesis. Proc Natl Acad Sci USA 100: 8621-8623, 2003.

8. Busse A and Keilholz U: Role of TGF- $\beta$ in melanoma. Curr Pharm Biotechnol 12: 2165-2175, 2011.

9. Lasfar A and Cohen-Solal KA: Resistance to transforming growth factor $\beta$-mediated tumor suppression in melanoma: are multiple mechanisms in place? Carcinogenesis 31: 1710-1717, 2010.

10. Malaponte G, Zacchia A, Bevelacqua Y, et al: Co-regulated expression of matrix metalloproteinase-2 and transforming growth factor-beta in melanoma development and progression. Oncol Rep 24: 81-87, 2010.

11. Goel MK, Khanna P and Kishore J: Understanding survival analysis: Kaplan-Meier estimate. Int J Ayurveda Res 1: 274-278. 2010.

12. Massagué J: TGFbeta in Cancer. Cell 134: 215-230, 2008.

13. Leivonen SK and Kähäri VM: Transforming growth factor-beta signaling in cancer invasion and metastasis. Int J Cancer 121: 2119-2124, 2007.

14. Albino AP, Davis BM and Nanus DM: Induction of growth factor RNA expression in human malignant melanoma: markers of transformation. Cancer Res 51: 4815-4820, 1991.

15. Bursch W, Oberhammer F and Schulte-Hermann R: Cell death and its protective role in disease. Trends Pharmacol Sci 13: 245-251, 1992.

16. Schmid P, Itin P and Rufli T: In situ analysis of transforming growth factor-betas (TGF-beta 1, TGF-beta 2, TGF-beta 3), and TGF-beta type II receptor expression in malignant melanoma. Carcinogenesis 16: 1499-1503, 1995.

17. Van Belle P, Rodeck U, Nuamah I, Halpern AC and Elder DE: Melanoma-associated expression of transforming growth factor-beta isoforms. Am J Pathol 148: 1887-1894, 1996.

18. Rodeck U, Bossler A, Graeven U, et al: Transforming growth factor $\mathrm{b}$ production and responsiveness in normal human melanocytes and melanoma cells. Cancer Res 54: 575-581, 1994.

19. Krasagakis K, Tholke D, Farthmann B, Eberle J, Mansmann U and Orfanos CE: Elevated plasma levels of transforming growth factor (TGF)-b1 and TGF-b2 in patients with disseminated malignant melanoma. Br J Cancer 77: 1492-1494, 1998. 